\title{
Unprecedented Protein Divergence within a T3SS Family
}

2

3 Azzeldin Madkour ${ }^{1}$, Bian Almessiry ${ }^{1}$, Bertha González-Pedrajo ${ }^{2}$ and Brendan Kenny ${ }^{1 *}$

$4 \quad{ }^{1}$ Biosciences Institute, Faculty of Medical Sciences, Newcastle upon Tyne, NE2 4HH, UK.

$5 \quad{ }^{2}$ Departamento de Genética Molecular, Instituto de Fisiología Celular, Universidad Nacional

6 Autónoma de México, Ciudad de México, Mexico

$7 \quad *$ Correspondence: $\underline{\text { brendan.kenny@ncl.ac.uk }}$

9 Selection pressure drives rapid emergence of antibiotic resistance mechanisms promoting searches for therapeutic targets in bacterial processes needed for virulence, not viability, which include the Type Three Secretion System (T3SS). Distinct T3SS families evolved from the flagellar export apparatus where remaining homology hinders development of anti-T3SS specific therapies. Around 15 proteins that are highly-conserved within, but not between T3SS families yet such divergence is rarely leveraged, to promote understanding, due to unknown evolutionary histories. Here we document unprecedented divergence in two 'LEE' T3SS family members. Interchangeability studies uncover unusual LEE biology (eg 2-orf genes) and illustrate each T3SS protein can tolerate dramatic change. Functional defects (12 proteins) and novel phenotypes enabled studies that reveal i) pathotype-specific protein functionality, ii) T3SS crosstalk with other processes, and iii) potential therapeutic targets. The work provides resources and testable predictions for further discoveries and will promote comparable studies between distinct T3SS families.

23 Keywords: LEE; T3SS; E.tarda; S.salamae; enteropathogenic; E.coli; EPEC; domainswapping; interchangeability; therapeutic targets; divergence. 


\section{Introduction}

26

The action of antibiotics that target physiologically important bacterial processes such as flagellar movement or cell wall biosynthesis are rapidly undermined by the evolution of resistance mechanisms (Lyons and Strynadka, 2019; Roope et al., 2019). As stated by the World Health Organisation (2021) “Antibiotic resistance is one of the biggest threats to global health, food security, and development today.". There is an emerging interest in identifying therapeutic targets against processes important for virulence, but not viability, such as Type Three Secretion Systems; T3SSs (Lyons and Strynadka, 2019; Marshall and Finlay, 2014). Transfer, via T3SSs, of 'effector' proteins into target cells drives physiology-altering changes underpinning many notorious diseases of man, animals, and plants (Coburn et al., 2007; Kenny and Valdivia, 2009). This 'injectisome' organelle evolved from the flagellar export system where significant homology hinders the development of anti-T3SS specific therapeutics (Lyons and Strynadka, 2019).

A model T3SS is provided by the Attaching and Effacing (A/E) family of enteric pathogens comprising Citrobacter rodentium, E.albertii, enteropathogenic- (EPEC) and enterohemorrhagic- (EHEC) E.coli strains (Bhatt et al., 2019; Gaytan et al., 2016; Lyons and Strynadka, 2019). This injectisome (Figure 1A) is encoded on a, horizontally-acquired, region called LEE (Locus of Enterocyte Effacement) alongside genes for transcriptional regulators, a muramidase (EtgA), protein of unknown function (Rorf1), chaperones (aid T3SS substrate stability/export process), effectors and Intimin surface protein (Bhatt et al., 2019; Gaytan et al., 2016; Lyons and Strynadka, 2019). High conservation (>80\% identity) between A/E pathogen T3SS protein homologs is considered to reflect functional constraints while the more divergent nature of extracellular components ( $>55 \%$ identity) - translocators, effectors, Intimin - is associated with exposure to host defense mechanisms (Bhatt et al., 2019; Castillo et al., 2005; Perna et al., 1998). 
51 from 5 families where homologs share as little as 21\% similarity (Diepold and Wagner, 2014).

52 Such divergence argues for selection pressure driving changes beneficial to the host bacteria's

53 lifecycle leading to a pathotype-specific T3SS. While such divergence provides opportunities

54 for interrogating T3SS protein biology and developing anti-T3SS (broad- or pathotype-

55 specific) therapeutics, it is rarely leveraged due to unknown evolutionary histories (Klein et al., 56 2017).

Here we describe how our interest in an apparently degenerate LEE region led to the uncovering of two, overlooked, examples of unprecedented divergence within an evolutionary closely-related T3SS family. We reveal this region is not degenerate but has unusual biology while studies with the homologs i) undermine the idea of high LEE T3SS protein conservation reflecting functional constraints, ii) illustrate many, if not all the T3SS proteins possess pathotype-specific functionality, iii) reveal T3SS crosstalk with other processes, iv) provide a strategy for identifying T3SS- and/or pathotype-specific therapeutic targets, v) forward testable predictions and vi) describe phenotypes and tools to enable future discoveries. 
67

\section{RESULTS}

\section{Unprecedented protein divergence within the LEE T3SS family}

The report of an invasive (non-A/E) fish pathogen, Edwardsiella tarda FPC503 (tarda), carrying a LEE region lacking all but one A/E pathogen-conserved effector (Nakamura et al., 2013) indicated repurposing for tarda-specific functionality. However, the apparent absence/truncation of many genes $(\sim 32 \%)$ prompted data re-interrogation revealed sequences for all but 8 (cesF, rorf1, grlA, grlR, map, espF-H; see Figure 1A); latter dispensable for A/E pathogenesis and T3SS functionality (Deng et al., 2004; Ruano-Gallego et al., 2015). Moreover, the analysis revealed a second effector (EspZ) and a 2-orf eae (encodes Intimin) gene while 4 genes were not truncated, but disrupted by sequencing-verified: $14 \mathrm{bp}$ insertion (escD), stop codon (escK) and frameshift (sepL, escL) mutation. However, 2-orf genes are expressible by, for example, ribosome-mediated mechanisms (Weiss, 1991). Unexpectedly, comparing the deduced protein sequences to their EPEC (E2348/69) counterpart revealed undocumented high divergence between LEE homologs: 21\%-73.4\% identity (Figure 1B).

\section{A majority of tarda LEE T3SS proteins functionally replace their EPEC counterparts}

Such unprecedented divergence prompted assessment of whether the tarda genes could functionally substitute their EPEC counterpart. Thus, tarda genes were PCR-cloned and introduced into the appropriate EPEC T3SS gene-deficient strain to assess T3SS functionality using two well-established assays (Kenny et al., 1997a; Kenny et al., 1997b). Strain genotype was routinely supported by PCR analysis (not shown).

These studies revealed 16 (of 28) genes functionally substituted, as exemplified by ces $A B$ that encodes a chaperone $39.6 \%$ identical to EPEC CesAB (Figure 2A). EPEC $\triangle$ cesAB secretes only one of three translocator proteins (Figure 2B) while Tir, the first and most abundantly-delivered effector (Mills et al., 2008), is not transferred into mammalian (HeLa) 
cells (Figure 2C). These defects were rescued by reintroducing EPEC or tarda cesAB (Figure 2B and 2C). Thus, despite high divergence (Figure 2A) tarda CesAB functionally replaces EPEC CesA/B.

Notably one substituting gene was interrupted (14bp insertion) separating the encoded $\mathrm{N}$-terminal (carries sole predicted sec pathway export signal and membrane-spanning region) and C-terminal (periplasmic) domains (Figures 2D, 2E and S1_i). It was predicted that tarda EscD would, as per EPEC EscD, produce a single full length polypeptide. However, adding an epitope tag (human influenza hemagglutinin; HA) at the Orf2 C-terminus revealed expression of a single Orf2-sized ( $\sim 28 \mathrm{kDa})$, not Orf1 $(\sim 14 \mathrm{kDa})$ or full length $(\sim 42 \mathrm{kDa})$, fusion protein. Disrupting orf1 (not shown) compromised the export process unlike HA-tagging Orf2 (Figure 2G) supporting independent Orf1/Orf2 expression. This work illustrates that tarda LEE 2-orf genes can produce functional proteins but perhaps not via predict ribosome-mediated mechanisms.

The 16 'functionally-substituting' members are 9 (of 10) basal body-export apparatus components, 6 (of 7) chaperones and 1 (of 8) ATPase-gatekeeper-sorting platform complex proteins (Figure 1B, 2 and S1_i-Xv). Functional interchangeability was not correlated with sequence divergence as members were distributed in all designated homology (\% identity) category: very low (21-40\%; EscO [21\%] $<$ CesL $<$ EscE $<$ EscG $<$ CesAB [39.6\%]), intermediate ( $>40-60 \%$; EscD $<$ EscI $<$ EscJ $<$ CesD2 $<$ EscT $<$ EscU) and highest $(>60-74 \%$;

EscS $<$ CesD $<$ EscC $<$ EscF $<$ EscR). Thus, many LEE T3SS proteins can accommodate substantial change without obvious impact on T3SS functionality.

\section{Complementation defects correlate with protein divergence}

Of the remaining 12 proteins, half were clearly expressed as restored some T3SS activity; latter exemplified by another 2-orf gene (Figure 3A) which encodes a SepL homolog (49.3\% 
identity; Figure 3B). As reported (Deng et al., 2005), EPEC $\Delta s e p L$ secretes, not translocator but effector proteins, most prominently Tir and NleA (Figure 3C). The mutant also fails to deliver Tir into HeLa cells with all defects rescued re-introducing EPEC sepL (Figure 3C and 3D). By contrast introducing tarda sepL only rescued one defect, partially, as enabled some Tir delivery (Figure 3C and 3D). Epitope-tagging Orf2 supported production of a full-length SepL protein (Figure 3E). The 6 'partial functionality' members (Figure S2 i-v) were a chaperone (CesT), 2 secretion regulators (SepL, EscP) and all translocators (EspA, EspB, EspD) distributed among the homology categories (Figure 1B): very low (EscP $<$ EspB), intermediate (SepL $<$ EspD $<$ CesT) and highest (EspA).

The final 6 tarda genes failed to replace their EPEC variant as exemplified by another 2-orf gene (Figure 3F) encoding an EscL homolog (26.8\% identity; Figure $2 \mathrm{G})$. Thus, the $\triangle e s c L$ mutant defect was rescued by plasmid re-introducing EPEC, not tarda escL (Figure $3 \mathrm{H}$ and 3I). HA-tagging supported expression of a full-length EspL protein (Figure 3J). Similar findings were obtained for other examined members: $\mathrm{SepD}$, EscQ, EscN and, final 2-orf encoded protein, EscK (Figure S3_i-iv). Notably tarda EscQ produced full length and Cterminal polypeptides (Figure 2K) as predicted for its EPEC variant (Gaytan et al., 2016). The 6 'complementation-null' members were 5 (of 8) ATPase-gatekeeper-sorting platform complex proteins and 1 (of 5) export apparatus proteins in the very low (EscQ $<$ EscL $<$ EscK $<$ SepD) or highest $(\mathrm{EscN}<\mathrm{EscV})$ homology categories (Figure 1B). The demonstration of 27 LEE tarda (includes four 2-orf) genes producing full-length and/or functional proteins suggests the complementation defects are not due to non-expression but reduced expression or, more likely, sequence divergence. To explore this hypothesis studies focused on the final 'complementation-null' group member, EscV as in highest homology category (66.3\% identity; Figure 1B and S3_v). The EscV C-terminal domain provides the 
Divergence within multiple docking sites (Figure 4A) prompted exchanging the entire Cterminal region for that from EPEC generating a chimera that rescued all export defects (Figure 4B and 4C) clearly linking the defects to divergence.

\section{Anti-T3SS therapeutic targets}

147 Next we examined if complementation defects could be leveraged to define protein features or residues important for T3SS functionality to provide potential therapeutic targets. This work focused on the partially-complementing translocator proteins (weakly restore Tir delivery; Figure 5A) as their extracellular location offer advantages for therapeutic development (Lyons and Strynadka, 2019). Notably, Tir delivered by EPEC expressing the most-divergent tarda translocator, EspB (37.8\% identity; Figure S2_i) stably interacted with Intimin unlike Tir delivered by the tarda EspA- or EspD-expressing strains (Figure 5A). Rescuing these defects by co-expressing the 3 tarda translocators (Figure 5B and $\mathrm{S} 2$ _i/ii) is suggestive of codivergence i.e. selection-driven change/s that negatively impact on T3SS functionality 'compensated' by change/s in partner protein/s. 5C) four chimera were initially generated (Figure 5C). Three chimera (C1-C3) reduced the levels or apparent molecular mass of examined effectors - Tir (Figure 5D) and EspF/EspB (Figure S2_ii) - suggesting EspA may have a cryptic role in regulating, directly/indirectly, T3SS substrate expression or stability levels. The fourth chimera (C4) rescued the defects (Figure 5D) implicated divergence in the final 54 residues prompting a focus on the most divergent area: residues 128-137 (0\% identity; Figure 5C). Swapping the 10 tarda residues for interaction (Figure 5C) reporting a key role for this with other, undefined, C-terminal features. 

provides a predicted secretion signal (Deng et al., 2015) and coil-coiled feature (CCF) involved in oligomerisation and membrane-insertion events (Chatterjee et al., 2015; Daniell et al., 2001). Replacing the final tarda 8 residues for EPEC's increased Tir delivery levels (Figure 6B) supporting it's predicted 'secretion signal' role and linking the majority of the complementation defect to $\mathrm{CCF}$ region divergence. Disrupting the $\mathrm{CCF}$, by substituting 3 residues $\left(\mathrm{A}_{340}, \mathrm{~A}_{347}, \mathrm{Q}_{354}\right)$ to arginine, led to phenotypes (Daniell et al., 2001) equivalent to those of the tarda EspD variant. Absence of phenotypes following substitution of $\mathrm{A}_{340}$ or A340A347 residues (Daniell et al., 2001) suggests Q354 plays the key role. Notably, these three residues are conserved in all 50 examined $\mathrm{A} / \mathrm{E}$ pathogen EspD variants, including an unusually divergent one (EspDmulti). By contrast the corresponding tarda EspD residues were $\mathrm{A}, \mathrm{G}$ and $\mathrm{L}$ i.e. two non-conservative changes (Figure 6C). Surprisingly, the EspDmulti and triplesubstituted variants had predicted C-terminal CCFs (Figure 6D) and, whilst absent from tarda EspD, could readily be generated by changing two residues to their EPEC counterpart (Figure $6 \mathrm{E})$. These findings argue for $\mathrm{Q}_{354}$, not the CCF per se, being important for stable, EspD/EspAdependent, Tir/Intimin interaction. Attempts to substitute $\mathrm{Q}_{354}$ to its tarda counterpart, L, in untagged and N-terminal epitope-tagged EspD variants were unsuccessful (changed compromised protein expression or stability; not shown) suggesting this residues has other important roles in EPEC EspD biology. therapeutic targets by highlighting regions, features or specific residues important for T3SS functionality) for further exploration. 


\section{Pathotype-specific T3SS protein functionality}

192

To further support that phenotypes arising from expressing a variant (EPEC, tarda, chimera) can be leveraged to describe pathotype-specific functionality, studies were undertaken on a $\Delta s e p L$ mutant phenotype. The latter refers to observing faster migration of proteins through SDS-PA gels (most evident for those $>40 \mathrm{kDa}$ ) with this phenotype rescued by re-introducing EPEC, not tarda sepL (Figure 7A). Screening virulence factor-deficient strains revealed the phenotype was shared by non-pathogenic (K12) E.coli and, surprisingly, another EPEC E2348/69 strain (Yen et al., 2010), hereafter EPEC_J (Figure 7B). Genome sequencing EPEC_J reported a cryptic $\sim 50 \mathrm{~Kb}$ deletion (Figure S4) encompassing operons for two virulence-associated exopolysaccharides; O127 antigen and colanic acid. K12 cannot express its O-antigen genes (Blattner et al., 1997) thereby implicating this molecule. The latter was supported by the addition of purified O-antigen rescuing the phenotype (Figure 7B) and antiO127 western blot signals (Figure 7C). The phenotype is a readout of cellular O-antigen levels by its, direct/indirect, impact on protein migration through SDS-PA gels.

Screening a bank of 36 mutants (lack individual LEE genes) reported 17\% shared the sepL mutant phenotype (Figure 7D). Phenotype rescuing by re-introducing the appropriate EPEC, not tarda gene (Figure 7E) demonstrated pathotype-specific functionality, with SepL, for 3 chaperones (CesAB, CesD2, CesT), 2 basal body components (EscD, EscC) and an effector (EspF; no tarda homolog). The tarda variants fully (CesD, CesAB, EscD, EscC) or partially (CesT, SepL) substituted in T3SS functional assays. These findings provide further evidence for high divergence between LEE homologs reflecting the presence of pathotypespecific biology. 
Other LEE T3SSs

217 Literature interrogations revealed LEE in other (non-A/E) strains: Salmonella enterica subsp. salamae (salamae) and, a prediction, Shigella boydii 13 (Chandry et al., 2012; Walters et al., 2012). Examining the deduced salamae protein sequences reveal another, overlooked, example of unprecedented LEE T3SS family divergence; as little as $26.2 \%$ and $18.2 \%$ identity to EPEC and tarda counterparts, respectively (Figure 1B). This finding prompted functionality interchangeability studies, but only for the homologs of the 12 tarda complementationdefective genes. These salamae proteins are distributed among the 3 homology categories $(2$, 4 and 6 in lowest, intermediate and highest, respectively; Figure 1B) but each functionally replaced its EPEC counterpart (not shown). This finding emphasizes that LEE proteins can tolerate significant change.

To probe for other LEE-encoding non-A/E strains BLAST searches were undertaken to Shigella boydii 13 whose similarity scores ( $>98 \%)$ supported the strain acquiring LEE from EHEC (Walters et al., 2012). The analysis uncovered homologs for all 4 proteins in a recently sequenced strain, Citrobacter freundii NCTC6267 (embl accession UFWO01000001.1) with high identity $(>82 \%)$ to the salamae variants indicative of LEE horizontal transfer between these strains. 
Discussion

Uncovering two examples of unprecedented divergence within an evolutionarily closelyrelated T3SS family has led to the discovery i) that all LEE T3SS proteins can tolerate dramatic change, ii) of tools and strategies to identify therapeutic targets and cryptic, pathotype-specific, functionality, and iv) of novel LEE biology. Moreover, the work provides unique resources and testable predictions with implications for other T3SS families and the identification of antivirulence (broad- or pathotype-specific) targets.

\section{LEE tarda: Novel biology and functionality}

Our interest in tarda LEE as a potential research tool prompted sequence data re-interrogation as $\sim 32 \%$ of genes, conserved in $\mathrm{A} / \mathrm{E}$ pathogens, were absent or truncated (Nakamura et al., while four $(10 \%)$ were not truncated but interrupted (insertion, nonsense or a frameshift mutation). The missing genes are non-essential accessory proteins (Deng et al., 2004; RuanoGallego et al., 2015) while each 2-orf gene was shown to produce a full length and/or functional protein. Indeed, our finding that all examined tarda LEE genes (32 of 33; did not examine nondata; not shown) provides the first, albeit indirect, evidence for this region encoding a functional injectisome.

The expression/functionality of 2-orf genes indicates involvement of ribosomemediated mechanisms; latter linked to regulating cellular processes including T3SSs (Weiss, 1991). We predict such regulation may functionally replace absence of LEE GrlA/GrlR homologs which modulate EPEC LEE gene transcription in response to environmental signals (Padavannil et al., 2013). The predicted involvement of ribosome-jumping, -readthrough and - 
not produce a single polypeptide but independently expressed Orfs. The latter also argues for unusual tarda EscD biology as questions how the periplasmic domain (Orf2) could access this compartment and function with Orf1 (cytoplasmic and transmembrane domain) to form a membrane-spanning ring structure (Gaytan et al., 2016). Studies on other tarda genes may reveal other non-conventional biology.

\section{Challenging T3SS dogma}

A pivotal discovery was the identification of LEE T3SS proteins from two non-A/E strains (E.tarda and S.salamae) displaying unheard levels of divergence relative to their EPEC homolog and in deed each other: as little as 18.2\% (tarda/salamae), 21\% (tarda/EPEC) and $26.2 \%$ (salamae/EPEC) identity. The latter contrasts to $>80 \%$ identity between $\mathrm{A} / \mathrm{E}$ pathogen homologs (Bhatt et al., 2019; Castillo et al., 2005; Perna et al., 1998). Indeed, the similarity scores (as low as $32.4 \%$ ) being comparable to those between distinct families (Diepold and Wagner, 2014) suggests tarda and salamae LEE T3SSs represent distinct subfamilies. A beneficial role for these systems, whether by providing T3SS or other functions, is supported the discovery of closelt-related homologs in other strains: E.tarda is now a member of new species, E. anguillarum, that share, among other things, a conserved LEE region (Nakamura et al., 2013; Shao et al., 2015) with salamae LEE homologs in multiple strains (Desai et al., 2013). Illustrating that all 28 examined T3SS proteins (tarda or salamae variant) can accommodate dramatic change (insertions, deletions, synonymous substitutions) questions the idea that high conservation between $\mathrm{A} / \mathrm{E}$ pathogen homologs reflects structural constraints (Bhatt et al., 2019; Castillo et al., 2005; Perna et al., 1998). By contrast, the findings argue that evolutionary pressure can in fact dramatically alter each protein with selection of changes most beneficial to the strain's lifecycle leading to a pathotype-specific T3SS.

\section{Cryptic T3SS protein biology}


The idea that divergence reflects pathotype-specific functionality was first suggested by identifying phenotypes linked to expressing a specific variant (EPEC, tarda, chimera). The hypothesis was clearly verified by studies on one phenotype as it revealed key roles for 7 EPEC LEE proteins in controlling the cellular level of another virulence factor, O-127 antigen; latter co-expressed with LEE (Hazen et al., 2015). Crucially, pathotype-specific biology was demonstrated by re-introducing the EPEC gene (not tarda variant) rescuing the phenotype; noting the tarda variants functionally-substituted (fully or partially) in T3SS assays. These findings not only support the emerging concept of EPEC LEE T3SS proteins possessing cryptic functions (Katsowich et al., 2017; Pal et al., 2019) but extends it by demonstrating that they can possess pathotype-specific biology. We predict that most, if not all LEE T3SS proteins have pathotype-specific functions involved, not in the T3SS export process but to coordinate specific T3SS events with other cellular processes.

Of note, discovering LEE protein/O-antigen crosstalk hinged on unearthing a cryptic undocumented $50 \mathrm{~Kb}$ deletion in a provided strain (Yen et al., 2010) revealing another example of unintentional genomic alteration (Cepeda-Molero et al., 2017). The latter challenge the EPEC genome stability concept (Nisa et al., 2013) and cautions on the use of these strains and engineered derivatives.

\section{Therapeutic targets}

The discovery that LEE T3SS proteins possess pathotype-specific biology (linked to crosstalk with other cellular processes) opens up avenues of research for uncovering therapeutic targets in T3SS proteins features not critical for T3SS export process or components in processes modulated by the T3SS protein. For example determining how any of the 7 EPEC LEE proteins (a gatekeeper, an effector, 2 basal body components, 3 chaperones) control EPEC O-antigen levels may provide strategies to block such crosstalk. We propose CesT's role relates to it 
binding the post-transcriptional regulator, CsrA, which controls many cellular processes including expression of the EPEC T3SS (via binding mRNAs including sepL-related) and revealed a myriad of phenotypes that represent future opportunities to uncover additional pathotype-specific biology and/or T3SS crosstalk.

T3SS-specific therapeutic targets were forwarded by domain-swapping experiments

317 (between complementation-defective and EPEC variants) as revealed regions, features or residues important for T3SS functionality. Indeed, such studies can uncover new phenotypes (suggestive of cryptic functionality) and biological insights that may promote therapeutic development. The latter is illustrated studies on the extracellular translocators revealing an EPEC EspA-EspD relationship underpinning a key pathogenic event i.e. stable interaction of the host membrane-inserted Tir effector with EPEC's Intimin surface protein (Kenny et al., 1997b; Marches et al., 2000). The domain-swapping experiments linked complementation defects to s 10 residue region in EspA - part of an extracellular hypervariable domain (Crepin et al., 2005) (EHVD) - and a specific residue within EspD's C-terminal coil-coil feature (CCF), not the CCF per se. EspD interacts with, and 'caps' the EspA filament (Gaytan et al., 2016) with the capping function, based on orthologues (Dey et al., 2019), via EspD's N-terminal domain. Our findings forward a model whereby EspD transition from its filament 'capping' to 'membrane-inserting' conformation enables CCF-EHVD interaction needed for efficient Tir delivery and stable Tir-Intimin interaction. Verifying this prediction would provide support this extracellular interaction as a valid therapeutic target. Understanding the key role for $\mathrm{Q}_{354}$ within the EspD C-terminal CCF region could promote the development of therapeutic (peptides, small molecule, antibody) reagents. Undoubtedly, similar studies on the remaining 10 complementation-defective tarda variants will uncover more phenotypes, pathotypespecific functionality and putative therapeutic targets. 


\section{Research and bioinformatics tools}

338 Uncovering divergent LEE protein homologs that do (16 tarda and, undoubtedly, all 28 339 salamae proteins) and do not (12 tarda proteins) functionally replace their EPEC counterpart 340 provides a powerful resource for experimental- and bioinformatics-related studies. Probing protein databases for homologs to define 'natural variation' can be highly beneficial by highlighting pathotype-specific changes. Divergent homologs can be employed to, for example, i) in co-immunoprecipitation/mass spectrometry studies to reveal partner differences and may also highlight possible crosstalk with another cellular processes while ii) defining tarda/salamae proteins structures for comparison to those published for $\mathrm{A} / \mathrm{E}$ homologs (Lyons and Strynadka, 2019; Marshall and Finlay, 2014) may reveal pathotype-specific features as therapeutic targets or for further investigation.

By contrast, comparing the 3 divergent (EPEDC/tarda/salamae) homologs provides numerous predictions. For example, about a quarter of the T3SS proteins whose homologs differed significantly (10-21 residue) due to terminal extensions or truncations. The latter is suggestive of i) LEE sequence errors, ii) 'pseudo' extensions; noting EPEC Ler is expressed from $2^{\text {nd }}$ ATG codon or, more likely, iii) pathotype-specific functionality. Moreover, while homologs for only two proteins (CesT, EscU) had no indels, suggestive of a size-constraint, three (EscP, EscI. EscE) had very large gap, average, scores (20-45\%) suggestive of unusual biology. High EscP divergence (Figure S5) at the amino acid (21\%-31\% identity; 39\%-54\% similarity) and indel (7\%-36\% gap; Figure 1B) level, could be useful for interrogating proposed 'ruler' and 'substrate switching' models; linked to protein size and/or terminal domain features (Gaytan et al., 2016). Another notable aspect was 'divergence anomalies' between partners, for example, $>74 \%$ similarity of SepL homologs versus $>42 \%$ for CesL chaperone suggesting 
Divergence anomalies may also aid understanding on why some T3SS substrates have multiple chaperones, for example, $\sim 66 \%$ similarity of EspD and the CesD2 homologs is suggestive of co-divergence whereas the higher $(>77 \%)$ value for CesD homologues indicates interacts with more conserved regions of EspD and/or, more likely, other protein/s.

\section{Constraint-releasing selection pressure?}

367 Why does high divergence in 12 tarda, but not corresponding salamae proteins compromise T3SS functionality when assessed in EPEC? Our linkage of complementation defects with codivergence is suggestive of unique pressure for T3SS proteins to tolerate changes which reduce/negate T3SS functionality by co-electing 'compensatory' changes in partner protein/s. Possible selection pressures may relate to LEE tarda-specific features such as i) 2-orf genes, ii) absence of GrlA, GrlR or EspH homologs, or iii) effector repertoire differences: EPEC - 6 LEE and >20 non-LEE-encoded (Nle) effectors (Gaytan et al., 2016); salamae - 3 LEE, and possibly a few Nle-like or putative effectors (Desai et al., 2013); tarda - 2 LEE but no Nle effectors (Dr Yoji Nakamura; personal communication). Interestingly, adjacent to tarda LEE are genes for an effector/cognate chaperone pair (not shown) that are homologous to proteins from another T3SS family (Yersinia). We propose this YopH-like effector is a tarda LEE T3SS substrate which required dramatic change in the LEE T3SS regulatory proteins to accommodate this effector/chaperone complex and control its timely entry into the LEE T3SS and delivery, via the translocon, into target fish cells.

Other LEE T3SSs

Blast searches using four EPEC proteins supports the possibility of LEE in other non-A/E strains as the findings are consistent with the prediction of Shigella boydii 13 acquiring EHEC 
and, a recently genome sequenced strain, Citrobacter freundii NCTC6267. Future sequencing

387 projects may uncover other strains encoding distinct LEE T3SSs to provide additional

388 bioinformatics and experimental tools for promoting the discovery of pathotype-specific

389 functionality, increasing understanding of T3SS protein biology and providing therapeutic

390 (broad- or pathotype-specific) targets.

391

392 Acknowledgements

393 E.tarda (strain and LEE DNA sequence) were provided by Dr Yoji Nakamura (Research 394 Center for Fish Diseases, National Research Institute of Aquaculture, Japan Fisheries Research 395 and Education Agency). We thank Dr Wendy Smith and Prof. Anil Wipat (School of 396 Computing Science Newcastle University) for genome sequencing EPEC_J. Research was 397 supported in Kenny lab. through PhD funding (A.M. Ministry of High Education, Libya; B.A. 398 Taibah University, Saudi Arabia) and BG-P lab. with grants from DGAPA, PAPIIT, UNAM 399 (IN212420) and CONACyT (180460).

400

401

402 


\section{References}

404 Berndt, V., Beckstette, M., Volk, M., Dersch, P., and Bronstrup, M. (2019). Metabolome and coli. Sci Rep 9, 138.

407 Bhatt, S., Edwards, A.N., Nguyen, H.T., Merlin, D., Romeo, T., and Kalman, D. (2009). The

RNA binding protein CsrA is a pleiotropic regulator of the locus of enterocyte effacement pathogenicity island of enteropathogenic Escherichia coli. Infection and immunity 77, 35523568.

Bhatt, S., Egan, M., Critelli, B., Kouse, A., Kalman, D., and Upreti, C. (2019). The Evasive Enemy: Insights into the Virulence and Epidemiology of the Emerging Attaching and Effacing Pathogen Escherichia albertii. Infection and immunity 87.

Blattner, F.R., Plunkett, G., 3rd, Bloch, C.A., Perna, N.T., Burland, V., Riley, M., Colladosequence of Escherichia coli K-12. Science (New York, NY 277, 1453-1474.

417 Castillo, A., Eguiarte, L.E., and Souza, V. (2005). A genomic population genetics analysis of the pathogenic enterocyte effacement island in Escherichia coli: the search for the unit of selection. Proceedings of the National Academy of Sciences of the United States of America $102,1542-1547$.

Cepeda-Molero, M., Berger, C.N., Walsham, A.D.S., Ellis, S.J., Wemyss-Holden, S., Schuller, S., Frankel, G., and Fernandez, L.A. (2017). Attaching and effacing (A/E) lesion formation by enteropathogenic E. coli on human intestinal mucosa is dependent on non-LEE effectors. PLoS pathogens 13, e1006706.

425 Chandry, P.S., Gladman, S., Moore, S.C., Seemann, T., Crandall, K.A., and Fegan, N. (2012).

426 A Genomic Island in Salmonella enterica ssp. salamae provides new insights on the genealogy 427 of the locus of enterocyte effacement. PloS one 7, e41615. 
428 Chatterjee, A., Caballero-Franco, C., Bakker, D., Totten, S., and Jardim, A. (2015). Pore-

429 forming Activity of the Escherichia coli Type III Secretion System Protein EspD. The Journal

430 of biological chemistry 290, 25579-25594.

431 Coburn, B., Sekirov, I., and Finlay, B.B. (2007). Type III secretion systems and disease.

432 Clinical microbiology reviews 20, 535-549.

433 Crepin, V.F., Shaw, R., Knutton, S., and Frankel, G. (2005). Molecular basis of antigenic 434 polymorphism of EspA filaments: development of a peptide display technology. J Mol Biol $350,42-52$.

436 Daniell, S.J., Delahay, R.M., Shaw, R.K., Hartland, E.L., Pallen, M.J., Booy, F., Ebel, F., 437 Knutton, S., and Frankel, G. (2001). Coiled-coil domain of enteropathogenic Escherichia coli type III secreted protein EspD is involved in EspA filament-mediated cell attachment and hemolysis. Infection and immunity 69, 4055-4064.

441 Strynakda, N.C., Puente, J.L., and Finlay, B.B. (2005). Regulation of type III secretion 442 hierarchy of translocators and effectors in attaching and effacing bacterial pathogens. Infection and immunity 73, 2135-2146.

444 Deng, W., Puente, J.L., Gruenheid, S., Li, Y., Vallance, B.A., Vazquez, A., Barba, J., Ibarra, J.A., O'Donnell, P., Metalnikov, P., et al. (2004). Dissecting virulence: systematic and functional analyses of a pathogenicity island. Proceedings of the National Academy of Sciences 447 of the United States of America 101, 3597-3602.

448 Deng, W., Yu, H.B., Li, Y., and Finlay, B.B. (2015). SepD/SepL-dependent secretion signals 449 of the type III secretion system translocator proteins in enteropathogenic Escherichia coli. Journal of bacteriology 197, 1263-1275. 
Desai, P.T., Porwollik, S., Long, F., Cheng, P., Wollam, A., Bhonagiri-Palsikar, V.,

452 Hallsworth-Pepin, K., Clifton, S.W., Weinstock, G.M., and McClelland, M. (2013).

453 Evolutionary Genomics of Salmonella enterica Subspecies. mBio 4, e00579-00512.

454 Dey, S., Chakravarty, A., Guha Biswas, P., and De Guzman, R.N. (2019). The type III secretion 455 system needle, tip, and translocon. Protein Sci 28, 1582-1593.

456 Diepold, A., and Wagner, S. (2014). Assembly of the bacterial type III secretion machinery. 457 FEMS Microbiol Rev 38, 802-822.

458 Gaytan, M.O., Martinez-Santos, V.I., Soto, E., and Gonzalez-Pedrajo, B. (2016). Type Three 459 Secretion System in Attaching and Effacing Pathogens. Front Cell Infect Microbiol 6, 129.

460 Gaytan, M.O., Monjaras Feria, J., Soto, E., Espinosa, N., Benitez, J.M., Georgellis, D., and 461 Gonzalez-Pedrajo, B. (2018). Novel insights into the mechanism of SepL-mediated control of effector secretion in enteropathogenic Escherichia coli. Microbiologyopen 7, e00571. D.A. (2015). RNA-Seq analysis of isolate- and growth phase-specific differences in the global transcriptomes of enteropathogenic Escherichia coli prototype isolates. Front Microbiol 6, 569.

467 Host cell attachment elicits posttranscriptional regulation in infecting enteropathogenic bacteria. Science (New York, NY 355, 735-739.

Kenny, B., Abe, A., Stein, M., and Finlay, B.B. (1997a). Enteropathogenic Escherichia coli 470 protein secretion is induced in response to conditions similar to those in the gastrointestinal 471 tract. Infection and immunity 65, 2606-2612.

472 Kenny, B., DeVinney, R., Stein, M., Reinscheid, D.J., Frey, E.A., and Finlay, B.B. (1997b).

473 Enteropathogenic E. coli (EPEC) transfers its receptor for intimate adherence into mammalian cells. Cell 91, 511-520. 
475 Kenny, B., and Finlay, B.B. (1997). Intimin-dependent binding of enteropathogenic

476 Escherichia coli to host cells triggers novel signaling events, including tyrosine

477 phosphorylation of phospholipase C-gamma1. Infection and immunity 65, 2528-2536.

478 Kenny, B., and Valdivia, R. (2009). Host-microbe interactions: bacteria. Current opinion in 479 microbiology 12, 1-3.

480 Klein, J.A., Dave, B.M., Raphenya, A.R., McArthur, A.G., and Knodler, L.A. (2017).

481 Functional relatedness in the Inv/Mxi-Spa type III secretion system family. Mol Microbiol 103, 973-991.

Lyons, B.J.E., and Strynadka, N.C.J. (2019). On the road to structure-based development of anti-virulence therapeutics targeting the type III secretion system injectisome. Medchemcomm $10,1273-1289$.

Marches, O., Nougayrede, J.P., Boullier, S., Mainil, J., Charlier, G., Raymond, I., Pohl, P., rabbit enteropathogenic Escherichia coli serotype O103:H2. Infection and immunity 68, 21712182.

Marshall, N.C., and Finlay, B.B. (2014). Targeting the type III secretion system to treat bacterial infections. Expert opinion on therapeutic targets 18, 137-152.

492

Mills, E., Baruch, K., Charpentier, X., Kobi, S., and Rosenshine, I. (2008). Real-time analysis of effector translocation by the type III secretion system of enteropathogenic Escherichia coli.

494 Cell host \& microbe 3, 104-113.

495 Nakamura, Y., Takano, T., Yasuike, M., Sakai, T., Matsuyama, T., and Sano, M. (2013).

496 Comparative genomics reveals that a fish pathogenic bacterium Edwardsiella tarda has 497 acquired the locus of enterocyte effacement (LEE) through horizontal gene transfer. BMC genomics 14,642 . 
Nisa, S., Hazen, T.H., Assatourian, L., Nougayrede, J.P., Rasko, D.A., and Donnenberg, M.S. bacteriology 195, 4476-4483.

Padavannil, A., Jobichen, C., Mills, E., Velazquez-Campoy, A., Li, M., Leung, K.Y., Mok,

Y.K., Rosenshine, I., and Sivaraman, J. (2013). Structure of GrlR-GrlA complex that prevents and secretion is controlled by an affinity switch in the type III secretion system of enteropathogenic Escherichia coli. The EMBO journal 36, 3517-3531.

Roope, L.S.J., Smith, R.D., Pouwels, K.B., Buchanan, J., Abel, L., Eibich, P., Butler, C.C.,

518 Ruano-Gallego, D., Alvarez, B., and Fernandez, L.A. (2015). Engineering the Controlled 519 Assembly of Filamentous Injectisomes in E. coli K-12 for Protein Translocation into Mammalian Cells. ACS Synth Biol 4, 1030-1041.

521 Shao, S., Lai, Q., Liu, Q., Wu, H., Xiao, J., Shao, Z., Wang, Q., and Zhang, Y. (2015). 
523 encoding two distinct T3SS and three T6SS gene clusters: Propose a novel species as

524 Edwardsiella anguillarum sp. nov. Syst Appl Microbiol 38, 36-47.

525 Walters, L.L., Raterman, E.L., Grys, T.E., and Welch, R.A. (2012). Atypical Shigella boydii

52613 encodes virulence factors seen in attaching and effacing Escherichia coli. FEMS Microbiol

527 Lett 328, 20-25.

528 Weiss, R.B. (1991). Ribosomal frameshifting, jumping and readthrough. Current opinion in 529 cell biology 3, 1051-1055.

530 Yen, H., Ooka, T., Iguchi, A., Hayashi, T., Sugimoto, N., and Tobe, T. (2010). NleC, a Type

531 III Secretion Protease, Compromises NF-kappaB Activation by Targeting p65/RelA. PLoS

532 pathogens 6, e1001231. 
Figure 1: T3SS Schematic and homolog comparison data. A) Schematic of EPEC E2348/69 (EPEC) T3SS composed of a basal body: 3 ring-like structures spanning inner/outer membranes $[\mathrm{EscD} / \mathrm{J} / \mathrm{C}]$ with a cavity enclosing the export apparatus ( 5 proteins [EscR-V] complex providing export 'entry' channel) connected, via adaptor protein [EscI], to hollow needle-like structure [EscF] protruding from the cell, ii) translocon: one translocator [EspA] extends the needle and 'capped' by 2 pore-forming translocators [EspB/D] whose insertion into the host membrane complete the effector-delivery conduit, and iii) ATPase-gatekeeper-sorting platform complex: $8[\mathrm{EscQ} / \mathrm{K} / \mathrm{L} / \mathrm{N} / \mathrm{O} / \mathrm{P} \& \mathrm{SepD} / \mathrm{L}]$ proteins beneath entry channel control the order/timing of substrate export. Also indicate are cytoplasmic chaperones/substrate complexes and predicted interactions. B) lists main function of T3SS proteins alongside amino acid (aa) number as well as, in bracketa, percentage identity, similarity, gap (reflects inserts/deletions) respectively when comparing indicated EPEC, Edwardsiella tarda (tarda) or Salmonella salamae (salamae) homologs. T3SSs (\%Sim) column shows reported (Diepold and Wagner, 2014) percentage similarity between homologs from multiple T3SS families. Colour coding: i) protein name in red highlights those proteins whose tarda homologue had no or little ability to functionally substitute its EPEC variant, ii) (\%Id;Sim;Gap) column: red, purple and green lettering highlights $\%$ identity is in the very low $(21 \%-40 \%)$, intermediate $(>40 \%-60 \%)$ or high (>61-74\%) category, respectively. alignment of EPEC and E. tarda (tarda) A) CesAB (chaperone) and D) EscD (basal body) homologs. Indicated, within brackets, are \% identity/similarity/gap scores, respectively with residues either identical (vertical line), similar (double dot), different (single dot) and absent (dashed line) residues. Location of predicted tarda EscD Orf1/Orf2 boundary and transmembrane segment are shown $(\mathrm{D}, \mathrm{E})$. Indicated strains were used to infect tissue culture media (B), HeLa cells (C, G) and lysogenic broth (F) before isolating secreted proteins (B), Triton X-100 soluble (Sol.; contains host cytoplasm and membrane proteins plus T3SSdelivered effectors) and insoluble (Ins.; contains host nucleus and cytoskeleton plus adherent bacteria) fractions $(\mathrm{C}, \mathrm{G})$ and total bacterial extracts $(\mathrm{F})$. Samples were resolved (SDS-PA gels) and proteins visualised by Coomassie blue staining (B) or Western blot analysis; latter detecting Tir effector $(\mathrm{C}, \mathrm{G})$ or HA-tagged proteins $(\mathrm{F})$. Arrows indicate position of secreted translocator (EspA, EspB, EspD) and autotransporter (EspC) proteins (B), unmodified $\left(\mathrm{T}^{0}\right)$ and host kinase-phosphorylated ( $\mathrm{T}^{\prime}$ ') Tir forms $(\mathrm{C}, \mathrm{G})$ and HA-tagged protein (F). Tir-Intimin interaction is evidenced by Tir T' ' in the Insol. fraction (Kenny et al., 1997b; Kenny and Finlay, 1997). Strains were non-pathogenic (K12) E.coli, EPEC, $\triangle$ ces AB (lacks chaperone) and $\triangle e s c D$ (lacks inner membrane ring protein) with or without indicated plasmids (Et denotes from $E$. tarda).

Figure 3: Examples of E.tarda variants displaying complementation defects. Gene sequences of 2-orf E. tarda (tarda) A) sepL and F) escL genes; position of frameshift mutation indicated (large red arrow). Sequence alignment of EPEC and tarda B) SepL and G) EscL homologs. Indicated strains were used to infect tissue culture media $(C, H)$, HeLa cells $(D, I)$ and lysogenic broth $(\mathrm{E}, \mathrm{J}, \mathrm{K})$ prior to isolating secreted proteins $(\mathrm{C}, \mathrm{H})$, Triton $\mathrm{X}-100$ soluble (Sol.) and insoluble (Ins.) fractions (D, I), or total bacterial extracts (E, J, K). Samples were resolved (SDS-PA gels) and proteins visualised by Coomassie blue staining $(\mathrm{C}, \mathrm{H})$ or Western blot; latter detecting Tir effector (D, I) or HA-tagged fusion proteins (E, J, K). Strains were non-pathogenic (K12) E.coli, EPEC, $\Delta$ sepL (lacks gatekeeper), $\Delta e s c L$ (lacks ATPase activity regulator) with or without indicated plasmids. Information on sequences, fraction composition, abbreviations and arrows as per Figure 2. 
Figure 4: Complementation defects-protein divergence linkage. Alignment of EscV Cterminal domain from EPEC and E. tarda (tarda) with red rectangle highlighting divergence in SepL (gatekeeper) binding sites (Portaliou et al., 2017). Indicated strains were used to infect tissue culture media (B) and HeLa cells (C) before isolating secreted proteins (B) and Triton X-100 soluble (Sol.) and insoluble (Ins.) fractions (C). Samples were resolved (SDS-PA gels) and protein visualised by Coomassie blue staining (B) or Western blot to detect the Tir effector (C). Strains used were EPEC, $\triangle e s c V$ (lack EscV export protein) with or without indicated plasmids; pesc $V_{E t}$ EPEC encodes a chimera protein; E. tarda 1-334; EPEC 345-674. Information on sequences, fraction composition, abbreviations and arrows as per Figure 2

Figure 5: Interchangeability and domain-swap experiments reveal co-divergence and changes underpinning complementation defects. Indicated strains were used to infected HeLa cells (3h or specified times) before isolating Triton X-100 soluble (Sol.) and insoluble (Ins.) fractions for Western blot analysis probing for the Tir effector (A, B, D). Sequence alignment of EPEC and E. tarda (tarda) EspA homologs showing key features and information on generated chimera $(C, D)$. Red rectangle highlights region where divergence is linked to complementation defect with natural variation (found in other A/E pathogen homologs) in this region indicated below the tarda sequence. Strains used were EPEC and strains lacking EspB $(\Delta e s p B), \operatorname{EspA}(\Delta e s p A)$ or $\operatorname{EspD}(\Delta e s p D)$ translocator proteins with or without indicated plasmids. Information on sequences, fraction composition, abbreviations and arrows as per Figure 2

Figure 6: Domain swapping reveals EspD features for Tir delivery and stable Tir-Intimin interaction. A) Sequence alignment of EPEC and E. tarda (tarda) EspD homologs showing key features and information on generated chimera (A, B). Red rectangle highlights region where divergence is linked to complementation defects (A). CCF region comparisons between EPEC/tarda and EPEC/Multi (A/E pathogen variant with many substitutions) sequences with natural variation (found in other $\mathrm{A} / \mathrm{E}$ pathogen homologs) indicated above the EPEC sequence (C). Red arrows highlight two non-conservative differences (C). CCF prediction output for indicated EspD variants $(\mathrm{D}, \mathrm{E})$. HeLa cells were infected with the $\Delta e s p D$ mutant carrying, or not, the indicated plasmid before isolating Triton X-100 soluble (Sol.) and insoluble (Ins.) fractions for Western blot analysis to detect the Tir effector (B). Information on sequences, fraction composition, abbreviations and arrows as per Figure 2

Figure 7. Divergence reflects pathotype-specific functionality. Indicated strains were grown in tissue culture media before isolating total bacterial extracts with samples resolved (SDS-PA gels) for Coomassie blue straining (A, B, D and, top panels, E) or Western blot analysis probing with anti-O127 antibodies ( $\mathrm{C}$ and, bottom panels, E). EPEC ext. and O-Antigen refers to adding EPEC cellular extracts (1:1 ratio) or commercial O-antigen $(1 \mu \mathrm{g})$ respectively before analysis. D) Screening EPEC mutants lacking individual LEE genes for sepL mutant phenotype. Altered protein migration is highlighted by red rectangles and arrow, with blue and green rectangles highlighting EPEC profile and mutants displaying $\triangle$ sepL mutant-like phenotype, respectively. Complementation data (E). Strains used were EPEC, EPEC-J (has cryptic 50Kb deletion), nonpathogenic E.coli (K12) and strains lacking a gatekeeper $(\Delta s e p L)$, a chaperone $(\Delta c e s T, \Delta c e s D$, $\triangle c e s A B)$, basal body protein $(\triangle e s c D, \Delta e s c C)$ or effector $(\triangle e s p F)$ with or without indicated plasmids (Et denotes from E. tarda). 
bioRxiv preprint doi: https://doi.org/10.1101/2021.03.31.437910; this version posted March 31 , 2021. The copyright holder for this preprint (which was not certified by peer review) is the author/funder, who has granted bioRxiv a license to display the preprint in perpetuity. It is made available under aCC-BY 4.0 International license.

A)

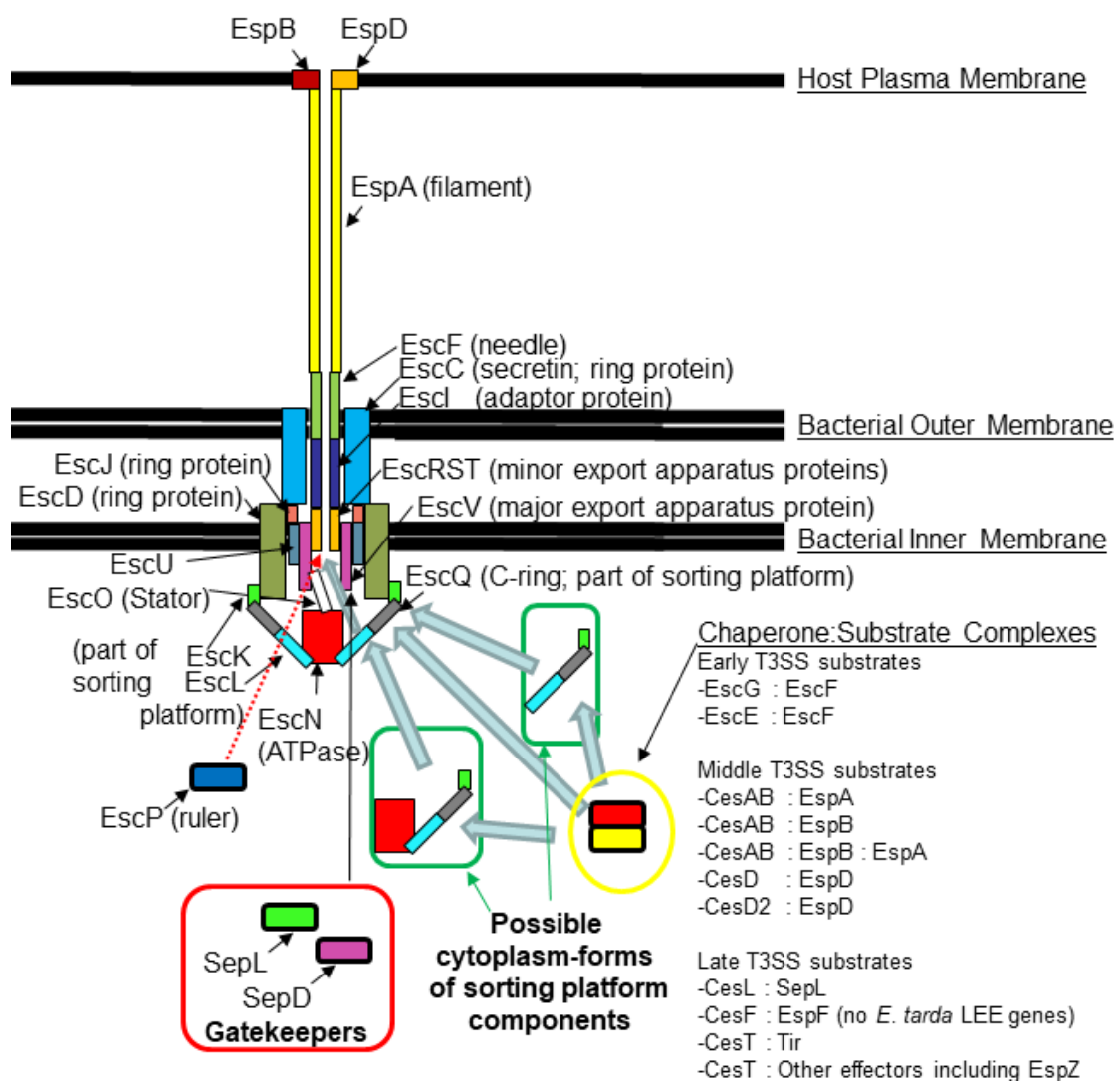

B)

\begin{tabular}{|c|c|c|c|c|c|c|c|c|}
\hline & Function & $\begin{array}{l}\text { EPEC } \\
\text { (aa) }\end{array}$ & $\begin{array}{l}\text { tarda } \\
\text { (aa) }\end{array}$ & $\begin{array}{l}\text { salamae } \\
\text { (aa) }\end{array}$ & $\begin{array}{c}\text { EPEC/tarda } \\
\text { (\%Id;Sim;Gap) }\end{array}$ & $\begin{array}{l}\text { EPEC/salamae } \\
\text { (\%Id;Sim;Gap) }\end{array}$ & $\begin{array}{c}\text { tarda/salamae } \\
\text { (\%Id;Sim;Gap) }\end{array}$ & $\begin{array}{c}\text { T3SSs } \\
\text { (\%Sim) }\end{array}$ \\
\hline & CHAPERONES & & & & & & & \\
\hline EscE & Class III (for EscF) & 72 & 76 & 76 & $35.4 ; 51.9 ; 12.7$ & $26.2 ; 61.9 ; 14.3$ & $27.4 ; 50.0 ; 9.5$ & \\
\hline EscG & Class III (for EscF) & 92 & 89 & 86 & $36.8 ; 56.8 ; 9.5$ & $47.8 ; 72.8 ; 6.5$ & $47.8 ; 72.8 ; 6.5$ & \\
\hline Ces.AB & Class II (for EspA \& EspB) & 107 & 104 & 102 & $39.6 ; 59.5 ; 9.9$ & $43.0 ; 69.2 ; 4.7$ & $39.9 ; 49.5 ; 14.4$ & \\
\hline CesD & Class II (for EspD \& EspB) & 151 & 153 & 150 & $64.3 ; 79.9 ; 2.6$ & $78.1 ; 90.7 ; 0.7$ & $60.4 ; 77.9 ; 3.2$ & \\
\hline CesD2 & Class II (for EspD) & 135 & 136 & 137 & $53.7 ; 66.9 ; 0.7$ & $67.2 ; 78.1 ; 1.5$ & $55.1 ; 65.2 ; 2.2$ & \\
\hline CesL & Class I (for SepL) & 117 & 107 & 117 & $30.1 ; 42.3 ; 17.9$ & $47.0 ; 73.5 ; 0.0$ & $28.0 ; 44.8 ; 20.8$ & \\
\hline \multirow[t]{3}{*}{ CesT } & $\begin{array}{l}\text { Class IB (for Tir, most LEE and } \\
\text { Many non-LEE-encoded effectors }\end{array}$ & 156 & 156 & 156 & $60.3 ; 80.1 ; 0.0$ & $84.0 ; 94.2 ; 0.0$ & $60.3 ; 78.2 ; 0.0$ & \\
\hline & & & & & & & & \\
\hline & SECRETION REGULATORS & & & & & & & \\
\hline EscO & Stalk (stimulates ATPase activity) & 125 & 122 & 126 & $25.0 ; 54.5 ; 12.9$ & $38.1 ; 65.1 ; 0.8$ & $32.5 ; 54.8 ; 3.2$ & 27 \\
\hline EscN & ATPase & 446 & 458 & 443 & $62.1 ; 76.4 ; 4.3$ & $76.2 ; 85.2 ; 0.7$ & $62.3 ; 76.5 ; 3.7$ & 92 \\
\hline SepD & Gatekeeper & 151 & 143 & 151 & $39.6 ; 63.6 ; 4.1$ & $58.9 ; 75.5 ; 0.0$ & $36.4 ; 59.7 ; 9.1$ & \\
\hline SepL & Gatekeeper & 351 & $343^{*}$ & 346 & $49.3 ; 74.4 ; 2.3$ & $66.7 ; 84.3 ; 1.4$ & $47.0 ; 73.8 ; 9.7$ & \\
\hline EscK & Sorting platform protein & 204 & $199 *$ & 199 & $34.4 ; 51.9 ; 9.9$ & $52.3 ; 75.4 ; 0.0$ & $29.2 ; 52.6 ; 7.2$ & 38 \\
\hline EscL & Stator (Negatively regulate ATPase) & 231 & $215^{*}$ & 227 & $26.8 ; 53.7 ; 6.9$ & $40.5 ; 64.9 ; 10.7$ & $29.4 ; 51.3 ; 14.7$ & 45 \\
\hline EscQ & C-ring (sorting platform) & 305 & 297 & 295 & $21.0 ; 44.1 ; 8.9$ & $37.7 ; 59.6 ; 7.7$ & $23.2 ; 48.3 ; 4.0$ & 38 \\
\hline \multirow[t]{3}{*}{ EscP } & Molecular ruler & 138 & 103 & 199 & $21.0 ; 39.1 ; 25.4$ & $31.2 ; 54.2 ; 6.9$ & $18.2 ; 32.4 ; 35.8$ & 33 \\
\hline & & & & & & & & \\
\hline & BASAL BODY & & & & & & & \\
\hline EscD & T3SS inner membrane ring (IM) & 406 & $416^{*}$ & 408 & $41.5 ; 57.6 ; 13.3$ & $57.4 ; 75.5 ; 0.5$ & $38.9 ; 55.9 ; 12.9$ & 21 \\
\hline EscJ & T3SS inner membrane ring (IM) & 190 & 179 & 187 & $53.1 ; 72.9 ; 7.8$ & $64.2 ; 74.2 ; 1.6$ & $57.1 ; 74.6 ; 6.3$ & 75 \\
\hline EscI & Rod (connects OM/IM rings) & 142 & 130 & 119 & $46.9 ; 63.3 ; 15.0$ & $56.2 ; 68.1 ; 18.8$ & $48.5 ; 68.5 ; 8.5$ & 47 \\
\hline EscC & T3SS outer membrane ring (IM) & 512 & 503 & 518 & $64.6 ; 80.3 ; 1.8$ & $78.6 ; 88.6 ; 1.5$ & $65.6 ; 79.3 ; 2.9$ & 75 \\
\hline \multirow[t]{2}{*}{ EscF } & Needle protein & 73 & 74 & 73 & $67.5 ; 87.8 ; 1.4$ & $87.7 ; 98.6 ; 0.0$ & $62.2 ; 87.8 ; 1.4$ & 91 \\
\hline & EXPORT APPARATUS & & & & & & & \\
\hline EscV & Main export apparatus protein & 675 & 674 & 675 & $66.3: 79.91 .6$ & $78.4 ; 88.9 ; 0.0$ & $67.3 ; 79.4 ; 1.3$ & 78 \\
\hline EscR & \multirow{4}{*}{$\begin{array}{l}\text { T3SS export apparatus: } \\
\text { contributes to recruitment and } \\
\text { regulation of substrate entry } \\
\text { into injectisome. }\end{array}$} & 217 & 218 & 217 & $73.4 ; 88.5 ; 0.5$ & $81.6 ; 93.5 ; 0.0$ & $75.2 ; 87.6 ; 0.5$ & 91 \\
\hline EseS & & 89 & 89 & 87 & $63.0 ; 82.6 ; 6.5$ & $82.0 ; 93.3 ; 2.2$ & $66.3 ; 87.6 ; 2.2$ & 94 \\
\hline EscT & & 258 & 259 & 258 & $56.1 ; 75.6 ; 2.7$ & $69.0 ; 84.1 ; 0.0$ & $53.3 ; 73.9 ; 1.9$ & 83 \\
\hline \multirow[t]{3}{*}{ EseU } & & 345 & 345 & 345 & $58.0 ; 78.8 ; 0.0$ & $74.8 ; 87.2 ; 0.0$ & $57.1 ; 77.7 ; 0.0$ & 84 \\
\hline & & & & & & & & \\
\hline & TRANSLOCATORS & & & & & & & \\
\hline Esp.A & \multirow{3}{*}{$\begin{array}{l}\text { EspA extends needle and is } \\
\text { capped by EspD/EspB which } \\
\text { insert into host membrane }\end{array}$} & 192 & 199 & 190 & $62.0 ; 74.3 ; 4.5$ & $73.8 ; 87.2 ; 4.1$ & $60.2 ; 76.1 ; 6.5$ & \\
\hline EspD & & 380 & 385 & 374 & $50.9 ; 66.9 ; 5.3$ & $61.9 ; 77.9 ; 4.2$ & $49.7 ; 67.7 ; 5.4$ & 33 \\
\hline EspB & & 321 & 340 & 330 & $37.8: 55.7: 12.2$ & $46.9 ; 67.4 ; 6.8$ & $36.5: 54.4: 10.2$ & 27 \\
\hline
\end{tabular}



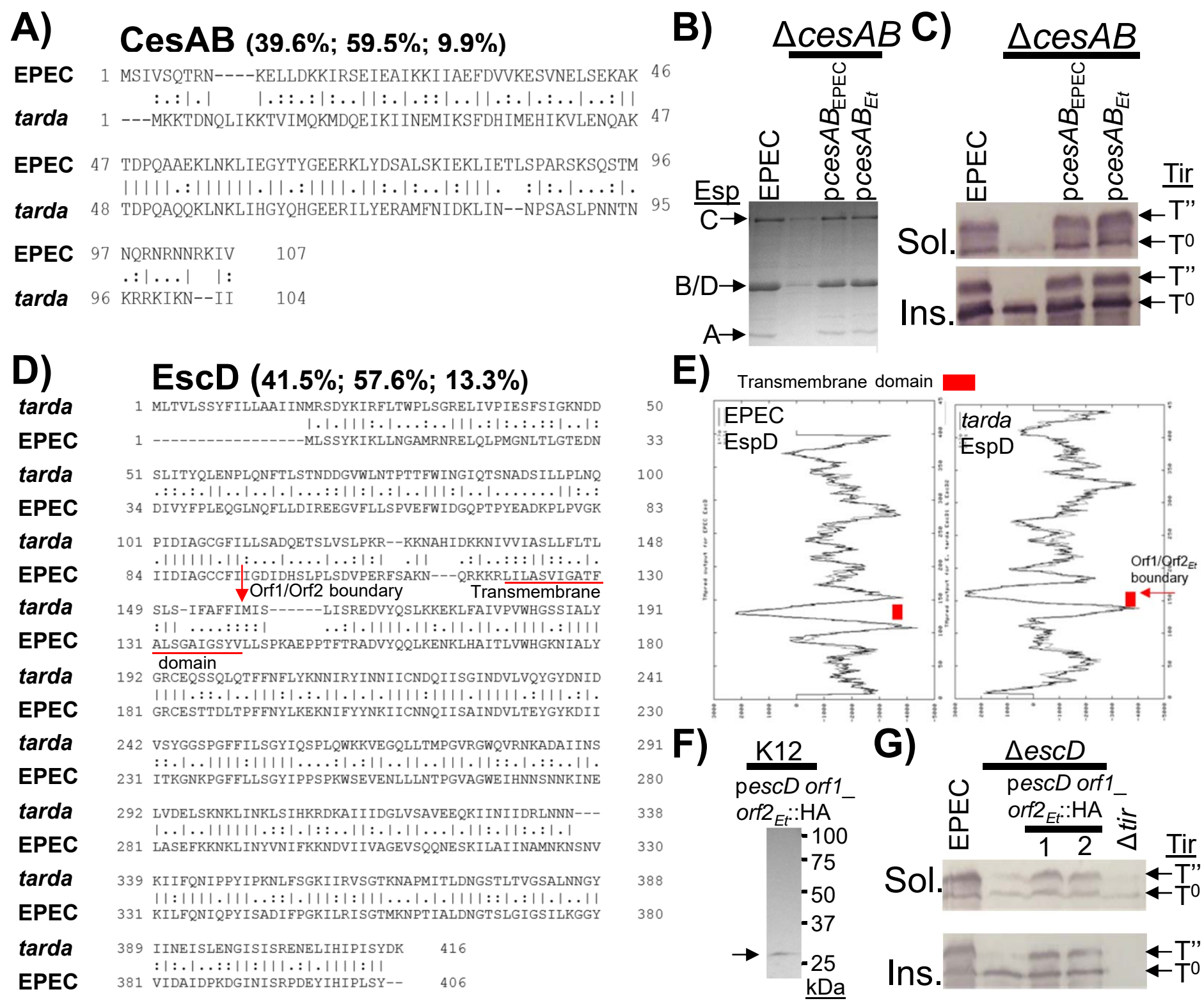

E)

Transmembrane domain
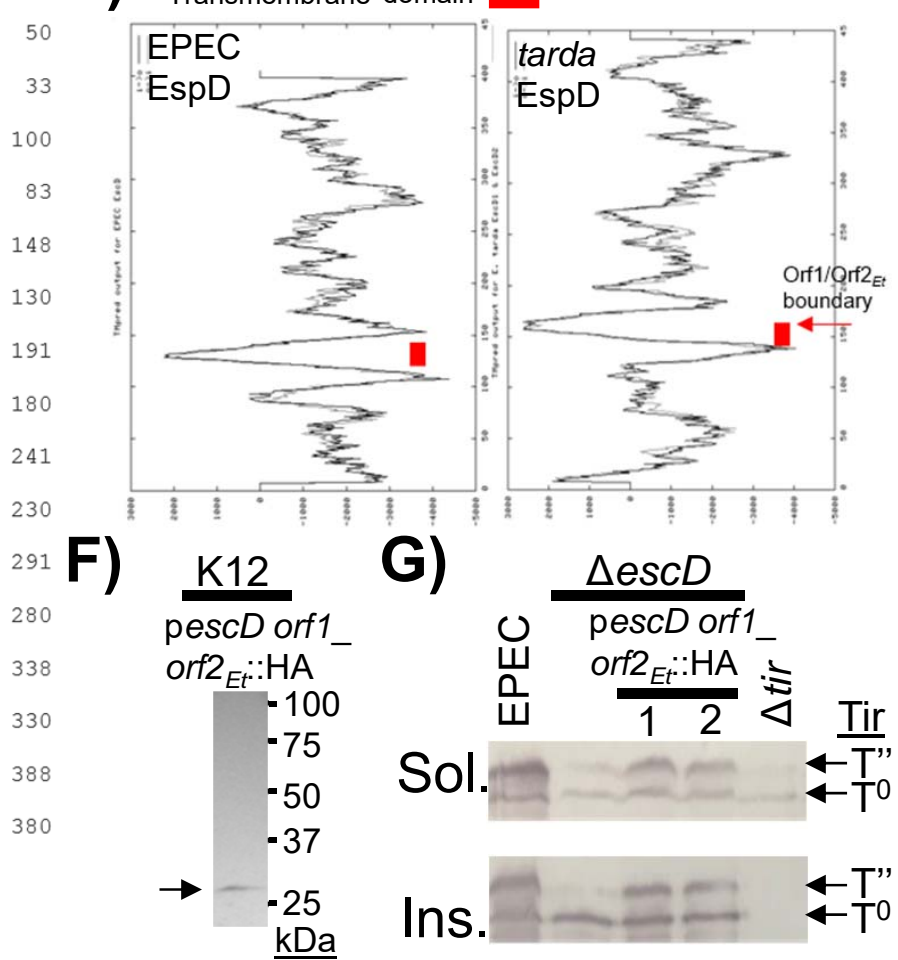

\section{Figure 2}




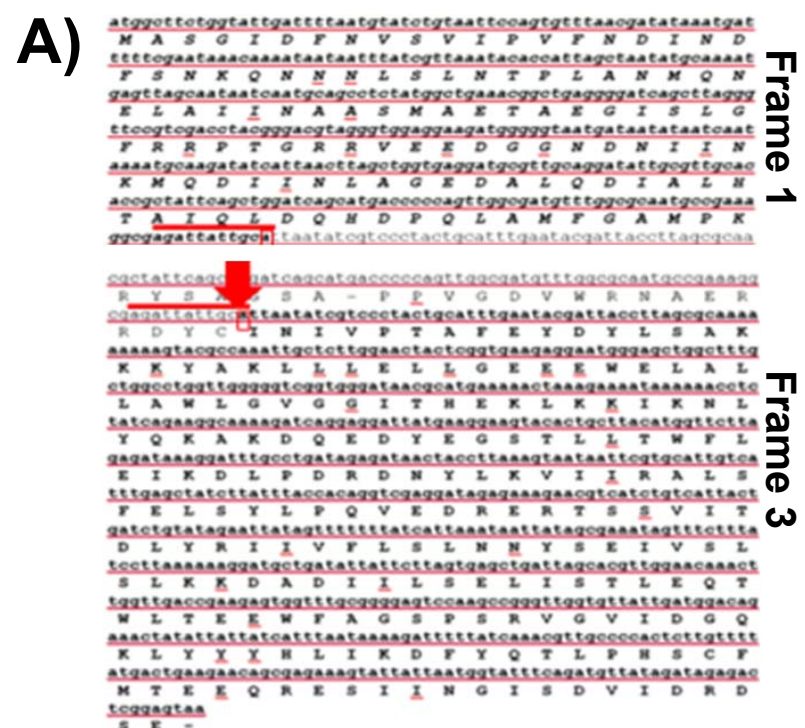

\section{B) SepL (49.3\%; 74.4\%; 2.3\%)}

tarda MASGIDFNVSVIPVFNDIN-DFSNK-----QNNNLSLNTPLANMQNELAI EPEC MANGIEFNQNPASVENSNSLDFELESQRLTQKNSSNTSSPLINLQNELAM tarda INAASMAETAEGISLGFRRPTGRRVEEDGGNDNI INKMQDI INLAGEDAL EPEC ITSSSLSETIEGLSLGYRKGSARKEEEGTTIEKLLNEMOELLTLTDSDKI EPEC ITSSSLSETIEGLSLGYRKGSARKEEEGTT IEKLLNEMQELLTLTDSDKI
tarda QDIALHTAIQLDQHDPQLAMFGAMPKGEIIAYNIVPTAFEYDYLSAKKKY EPEC KELSLKNSGLLEQHDPTLAMFGNMPKGEIVALISSLLQSKFVKIELKKKY tarda AKLLLELLGEEEWELALLAWLGVGGITHEKLKKIKNLYQKAKDQEDYEGS EPEC AKLLLDLLGEDDWELALLSWLGVGELNQEGIQKIKKLYEKAKDEDSENGA tarda TLLTWFLEIKDLPDRDNYLKVIIRALSFELSYLPQVEDRERTSSVITDLY EPEC SLLDWFMEIKDLPEREKHLKVIIRALSFDLSYMSSFEDKVRTSSIISDLC

tarda RIIVFLSLNNYSEIVSLSLKKDADIILSELISTLEQTWLTEEWFAGSPSR EPEC RIIIFLSLNNYTDIIAISIKKDKDVILNEMLSIIEHVWLTEDWLLESPSR

tarda VGVIDGQKLYYYHLIKDFYQTLPHSCFMTEEQRESIINGISDVIDRDSE-- 343 EPEC VSIVEDKHVYYFHLLKEFFASLPDACFIDNEQRSNTLIMIGKVIDYKEDV
44
C)
$\Delta \operatorname{sepL}$

崫

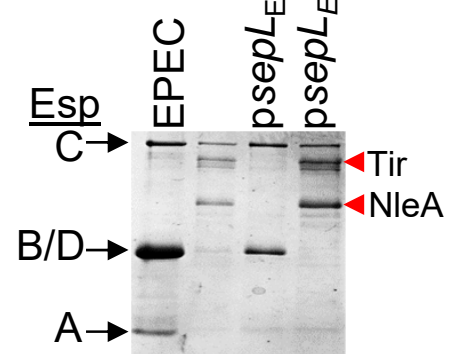

F)

atgaaaacaacacgctacagaaaaataaaattgagtaattttaatgaaaaaaaacactta

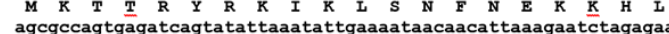
S A S E I S I I N I E N N N I R E S R E

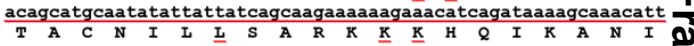
cgcagaagactcgcaattagactatggagatatcg taacaatattaacacgcattatcaa

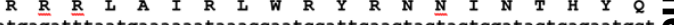

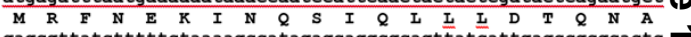
gagcgttatctttttctaaaagccatagagcaggcgcagttatcattgagcegcgcactc

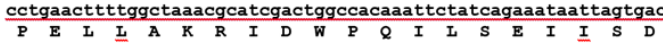
K I K K T S - M E I - K - Q R T K I S $\frac{\text { aattaaaaaaacaagt taaatggagatatagaaataacaaagaacgaaaatctcataatt }}{\mathrm{N}-\mathrm{K} N \mathrm{~N} \text { K I N G D I E I T K N E N I I I }}$ aatacagatagtattaatgcaacgattactaatgatagcaacatggacatcgataccata gtaatggaaaatcaatatataagaataacactatcgcccaaaaaacaaatagaaaacgcg

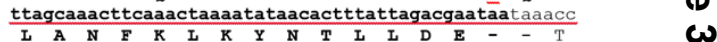

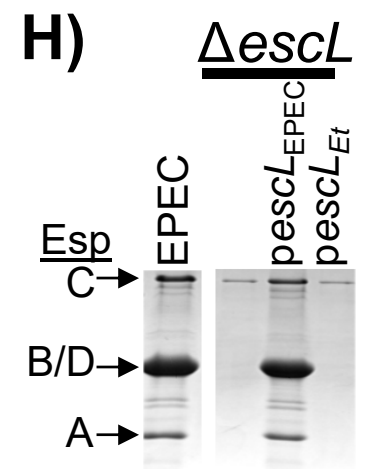

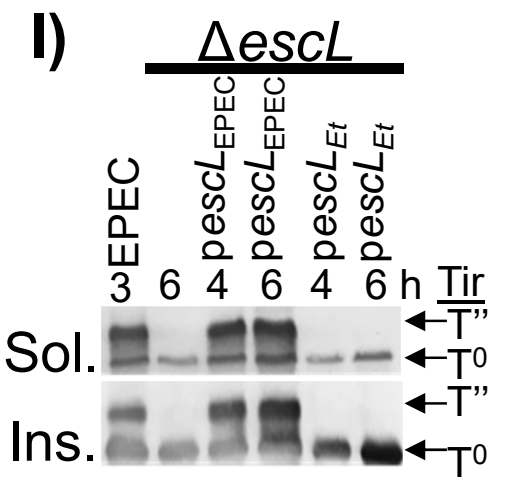

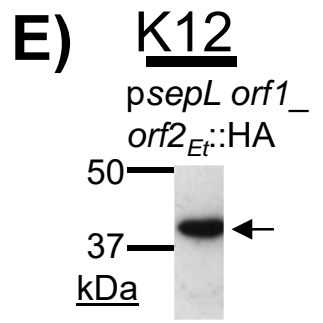

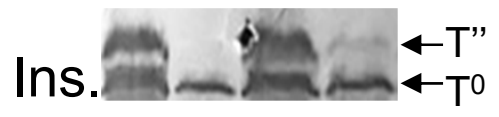

\section{G) EscL (26.8\%; 53.7\%; 6.9\%)}

EPEC MIYFLTDL IKFYCLMKLYEFKNIEIDLVLTEDI IPEDKLQEI IQSDDIIK 50

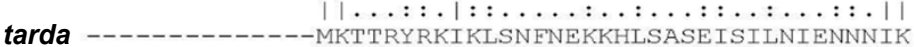

EPEC LARKKTYEHLLRARRKSKELKIESRKKIARKMIAMRERIRKNNKIKLDKE 100 tarda $.:|: \ldots \ldots|||,|:| \ldots::|\ldots| 1:::|,:: \ldots| \ldots \mid \ldots:$ : : : : : : : tarda ESRETACNILLSARKKKHQI KANIRRRLAIRLWRYRNNINTHYQMRFNEK 86

EPEC VNQSIKWVKDIQAIELVLMQDIMNKVHLSLTNALHSLDTSSRINWDDLIN 150 tarda INQSIQLLLDTQNAERYLFLKAIEQAQLSLSRALPEL-LAKRIDWPQILS 135

EPEC EVVRETLSNNNIVGAIKITKNPDIKLDPGEANNIQLINDANTPHNKIIIE 200

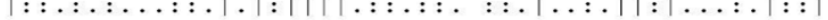
tarda EIISDKIKKTSLNGDIEITKNENLIINT-DSINATITNDSNMDIDTIVME 184 A Orf2
EPEC NEYIRITLDPLEQISILLNSEKDNYLSIIQE 231 tarda NOYIRITLSPKKOIENALANFKL KYNTILIDE

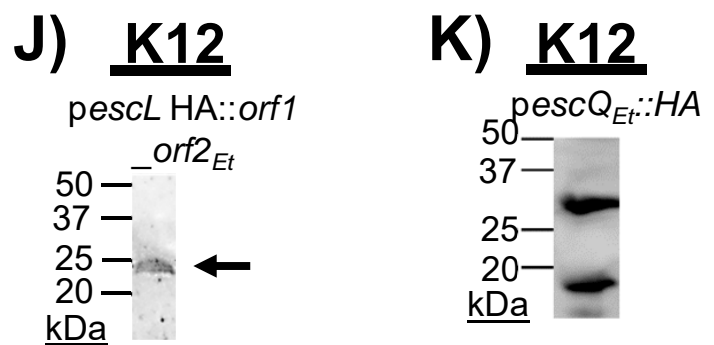



A) EscV C-terminal domain (58.3\%; $\mathbf{7 5 . 8 \% ; 0 . 3 \%}$
tarda ISPGAEPLI ILSSNIYSSDITQQIEVMRWNFFEESGIPLPKIIVNPVKN 395
EPEC KDDAIEVYLYQELVYKTFWENEKIIFFPNSNDFSFEYQKELLPYGRKVYK 445
tarda $.|| .1|. .1111 .:| 1 \ldots \ldots: . .1 \ldots \ldots: .111: .: 1.1 \ldots \ldots|1|$
tarda NDSAIEELEYQESIYKDTLIDDTVYFEAGHAE ISFE FVQEKLSTNSIVYK 445
EPEC TPLANEEIAISLGIKVVNNVNDAVVE YS ILIVSCCAREFIGVQETRYLMD 495

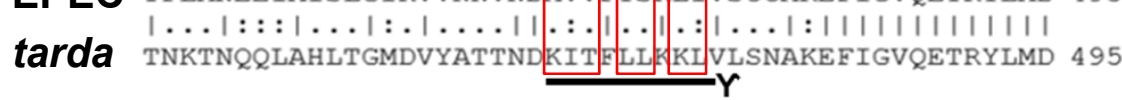
EPEC IMERQYSELVKELQRQLGLSKIVDILQRLVDEEISIRDLRTIFETLILWS 545

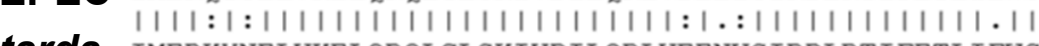
tarda IMERKYNELVKELQRQLGLSKIVDILQRLVEENVSIRDLRTIFETLIFWS 545
EPEC VKEKDVVILCEYVRVALRRHIISKHSNHGEMLSVWLIGSELENEMREAIR 595
tarda TKEKDVVILCEYVRIALRRHILGRYSVSGTLLNVWLIGSDIENELRESIR 595
EPEC QTSSGSYLNLSAERSSQLIASMNTIIDSNINGVILTSLDIRRYMKKLIEG 645

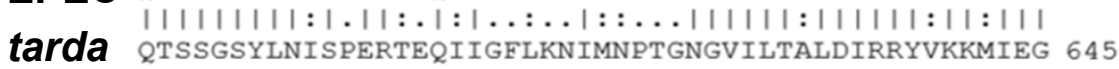
EPEC TIPTISVLSFeEVGNDIGLKVLGTINGye-
tarda SFPSVPVLSFEEVGNNIELKVLGTVNDFRA
t. 675
674
$\alpha \beta Y=$ SepL binding sites

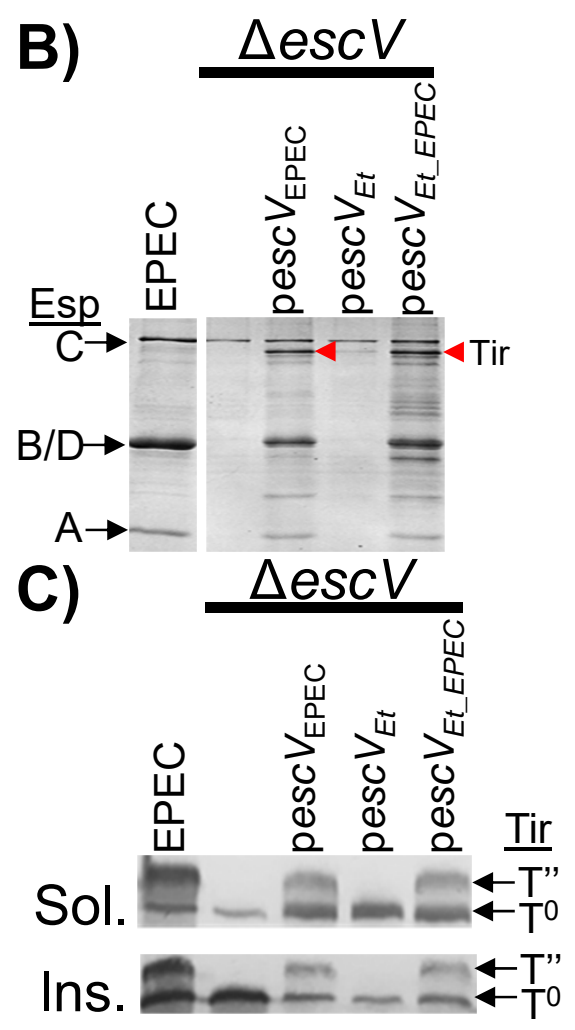

Figure 4 
A)

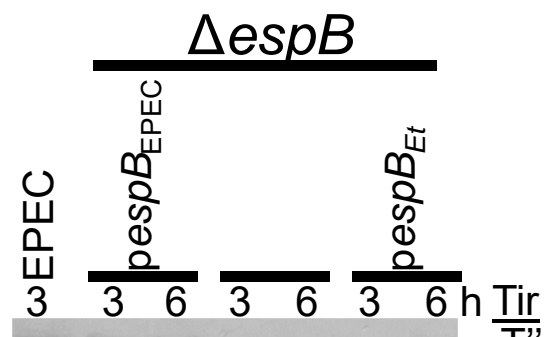

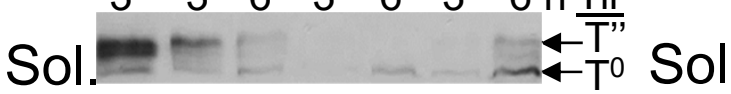
Ins.
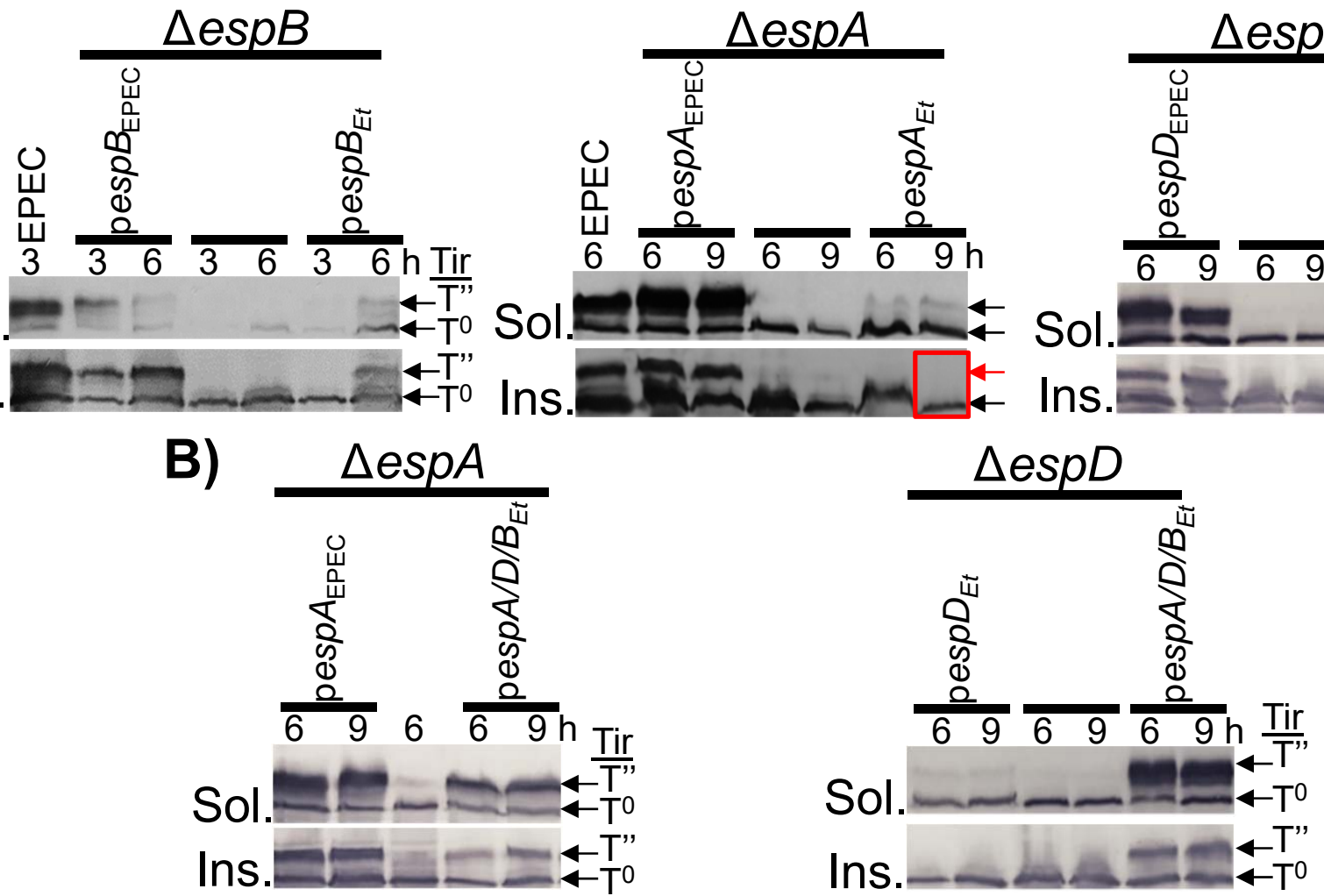

C) $\operatorname{EspA}(62.0 \% ; 74.5 \% ; 4.5 \%)$

EPEC-----MDTSTIASVASANASTSTSMAYDLGSMSKDDVIDLFNKLGVEO

tarda MFLIYRRIDDMSDISVGGGFQVDGT-LGYDLSSMSKADVQALFEKVGAFQ

STISVGGGQVDGT

EPEC AAILMFAYMYQAQSDLSIARFADMNEASKESTTAQKMANLVDAKIADVQS

tarda 111::1:.11.111.: ...11:111111.11.1111.111111111111

tarda AAIMLFSSMYSAQSKMTTKVAEMNEASKASTEAQRMENLYDARIADVOS

EPEC SSDRNARAQLPDEVISYINDPRNDITISEID-NINAQIGAGDLQTVRAA1 C2

tarda SSDKNTKVRLPOEVIDYINDPSNEIRISALSVGLTEANGAGDLQTVRAAL 149

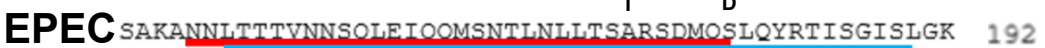

tarda $.|1|||||:|||::||:|||:||||||:|| .|||:||||||||||::| \mid$

tarda GARANNLTSVVNSNQLQIQQLSNTLNLMTSTRSDLQSLQYRTISGITIGK 199

Coil-Coil (EspA filament assembly) $\alpha$-helical (CesAB binding)

Coil-Coil (EspA filament assembly)
D)

49

Sol

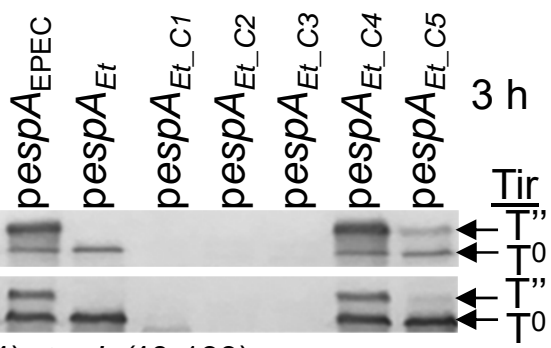

$\mathrm{C} 1=\mathrm{EPEC}(1-34) \operatorname{tarda}(40-199)$

$\mathrm{C} 2=\operatorname{tarda}(1-145) \_$EPEC(138-192)

C3=EPEC(1-66)_tarda(73-199)

C4=tarda(1-70)_EPEC(64-192)

C5=tarda(1-128)_EPEC(123-130)_tarda (138-199)

\section{Figure 5}




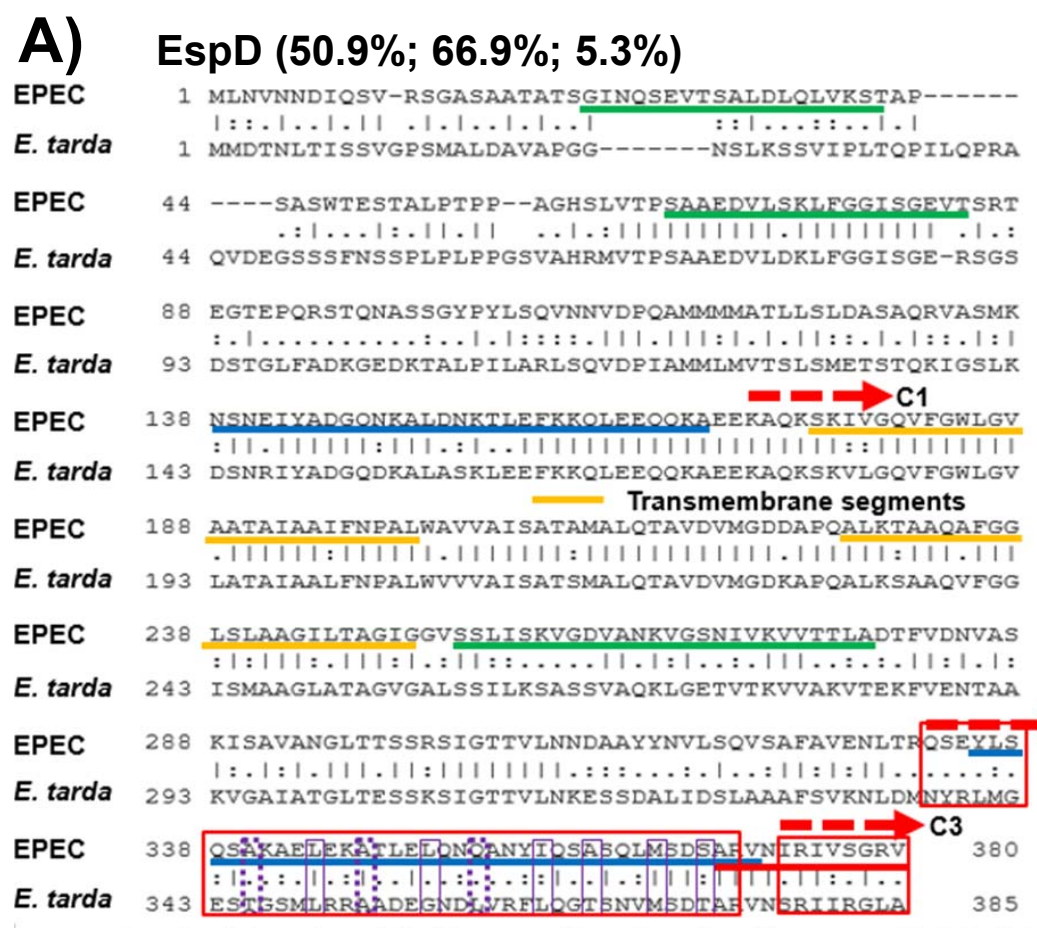

Amphipathic regions I, II, III - Secretion signal? Coil_Coil, I, II $\Pi$ a/d positions of heptads in predicted coil-coiled feature

(broken lines indicate residues substituted in triple mutant)

\section{C) EPEC QSARAELERATLELQNQANYIQSASQLMSDSAR \\ Multi ESARLELDRAASELQNQASYLQSVSQLMSDSAR}

\section{E $L$ DR $\stackrel{\text { R }}{S} M$ SS $L \quad$ V $K \quad I \quad A$}

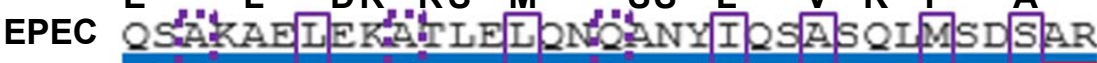

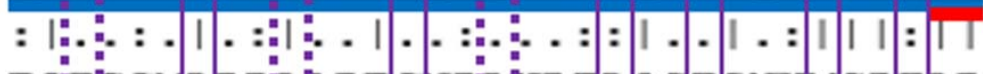

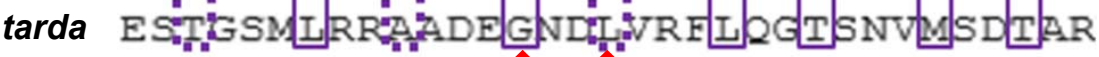

B)

43

43

87

92

137

142

\section{D)}
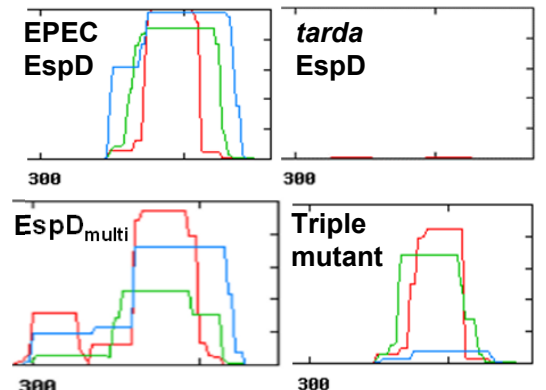

E)
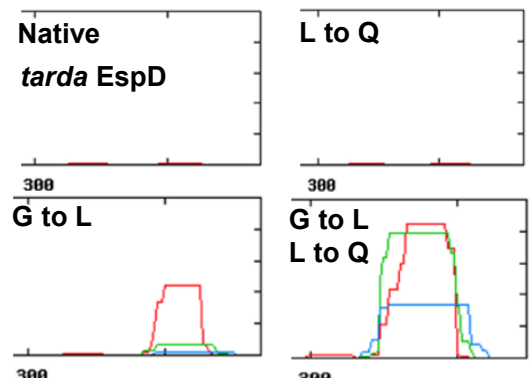

300

\section{Figure 6}




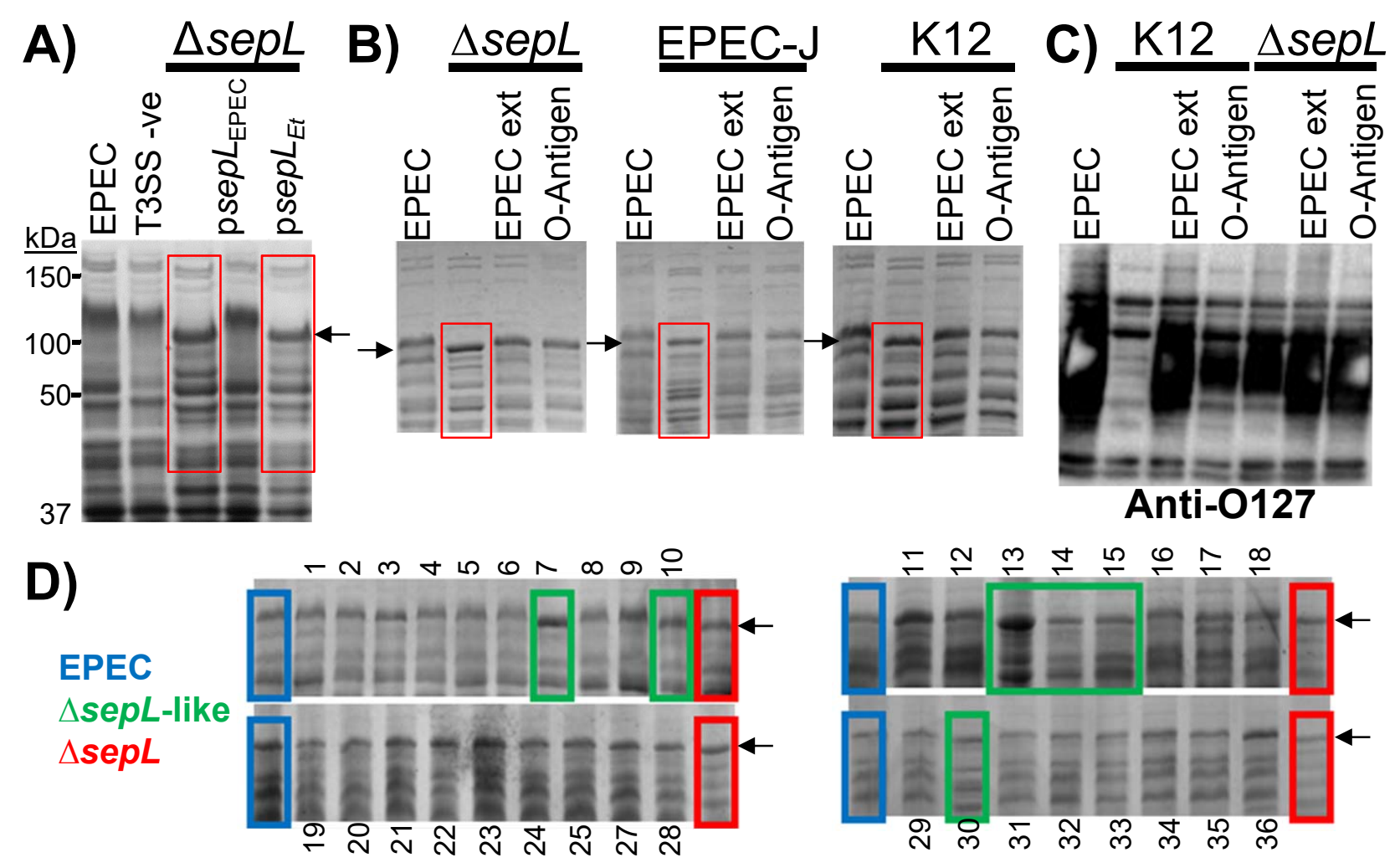

E)

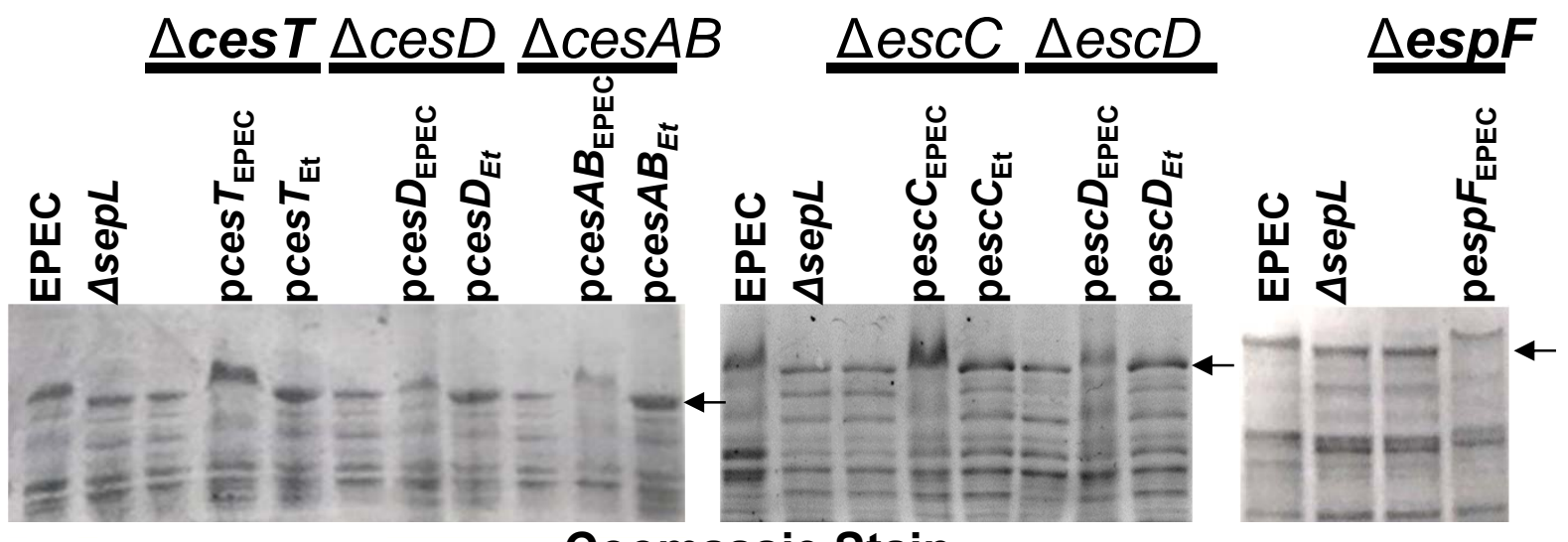

\section{Coomassie Stain}

\section{Figure 7}

\section{Anti-0127}

